\title{
Indian education: Opening a space for digital storytelling
}

Tiffany M. Locklear and Frances D. Hunt, UNC-Pembroke

\section{ABSTRACT}

Using an interpretive analysis of digital storytelling, we advance the conversation on ways Indian communities can rethink educational design. From an ethnohistorical context, we interrupt traditional pedagogy to grant voice and perspective to the Indigenous community. In this paper, we blend constructivism and personal digital stories to bring forth critical consciousness concerning mainstream educational practices. As an alternate, yet, innovative approach, we employ Unlocking Silent Histories, an educational design that aims to couple culture and learning. It does so by opening a space for teaching and learning that illuminates the Indigenous way. Our analysis reveals emerging themes of the Lumber River, community, and resilience.

Key Words: American Indian education, Indigenous, Native, Lumbee History, Digital Storytelling

et's be real; there are copious amounts of research on Indigenous teaching and learning and the positive implications "Indian teaching" has on the Indigenous population. Yet, Indigenous students' unique cultural backgrounds and heritages are often overlooked. There is a cursory nod to the Indigenous student, typically in November during Native American Indian Heritage month. Students endure the erroneous teaching of their history, most notably the role Christopher Columbus played in the "discovery" of the Indian. Indigenous youth often sit passively while critical consciousness is brushed away, watching their history "white-washed" by the inconsiderate masses. There have been efforts to address this lack of consideration for the Indian student. For example, to support Indigenous youth and educators alike, The Every Student Succeeds Act stresses the importance of embedding culture into the curriculum. Despite extensive research by Indigenous and non-Indigenous scholars and despite recommendations of The Every Student Succeeds Act, disconnections remain present between "Indian youth" and "teaching and learning". Martinez (2014) suggests, "American Indian students perceive a cultural bias against them in classroom curriculum as well as pedagogical practices" (p. 202). There is an antiIndigenous narrative and an anti-Indigenous curriculum permeating traditional classrooms. How do Native scholars counteract not only this narrative, but also mitigate the damage incurred from these thoughtless attacks on Native students' cultural identity?

In this paper, we interrupt the Columbus narrative, the designing of headdress feathers in November, and other inaccurate accounts to open a space of teaching and learning that leads to 
building critical consciousness in Indian communities. First, we analyze and respond to historical learning spaces for Indigenous youth and storytelling. Next, we focus on the art of storytelling in the Lumbee community. Finally, we introduce digital storytelling from a programmatic standpoint by exploring the pedagogy of Unlocking Silent Histories that aims to disrupt the colonial narrative. We do this by providing film analyses of the documentaries crafted by our Lumbee youth. This article offers an authentic alternative to Indigenous schooling by opening a space that allows our youth to create digital stories reflective of the Lumbee way.

\section{Theoretical Framework}

We draw on interpretative qualitative analysis and digital storytelling to understand the influence of telling our own tribal stories to and for our own people. To respect the importance of Native storytelling one must understand the result of outsiders writing our stories because "every view is a way of seeing, not the way" (Wolcott, 2008, p. 144). According to Hatch (2002), "Interpretation situates the researcher as an active player in the research process" (p. 180). Indigenous researcher interpretation allows us to write educational narratives utilizing our frameworks for the world of academia, our perspectives, and our voices. Brayboy and Deyhle (2000) point out that "insiders" can conduct good, rigorous research (p. 166). As insiders (members of the Lumbee people), we embrace the ethnohistorical frame of research, conducting an analysis of digital storytelling - drawing on our Indigenous perspectives - our voices - our way of seeing.

Utilizing the two approaches, we provide an analysis of how Indigenous students make sense of their culture and heritage through digital storytelling. We begin with the history of Lumbee storytelling and discuss the implications of losing oral accounts that are authentic, meaningful, and relevant to our people. To offer a 21st century, pedagogical approach for providing historical accounts, a space is opened for constructing our own narratives through digital storytelling. In telling our stories, we accept the responsibility for (re)shaping, (re)claiming, (re)writing, and more specifically (re)forming historical accounts through a digital lens. Locklear (2017) defined "re- as the colonized perspective of arrangement, presentation, and distribution within Indigenous communities" (p. 40). This interrupts historical educational norms while establishing a space of opportunity for our Lumbee youth, a marginalized group, who have, in many ways, been left behind.

\section{The Importance of Oral Traditions in Indigenous Culture}

Storytelling, or oral traditions, is part of Native culture, and it serves as a sustainable link to the past for Indigenous nations. Most importantly, storytelling serves as a safeguard for 
Indigenous culture. Scroggie (2009) explains, "Traditional stories have been passed from generation to generation through folktales, songs, rituals, chants and even artifacts. These oral narratives are critical historical components that pre-date written words. They explain the culture and how it came to be" (p. 76). Lowery (2018), a Lumbee historian, describes origin stories and how these stories provide explanation for identities. She writes:

Origin stories give meaning to identities like American, Lumbee, Christian, Jewish, Muslim, immigrant, refugee, and so many others. We determine who belongs partially through our knowledge of and loyalty to those stories. We create a nation, we share an identity by reconciling these different stories-the nation in question might be an American nation, a Lumbee nation, a Christian nation, a nation of immigrants, or something else entirely. (p.15)

The Lumbees created a nation of people who identify as Indigenous, and it is this belief that ties them to one another. Lowery (2018) acknowledges, "In my youth, I knew that I was Lumbee for one reason: I had a Lumbee family" (p. 15). Storytelling then, especially for the Lumbee, becomes uniquely important. These stories sustain our identity, and they tie us irrevocably to each other.

For the Lumbee, storytelling is used to propel the tribe's history from one generation to the next. The richness of our stories not only reflect our history, but also serve as a reminder of our strength to outsiders. For instance, the Battle of Hayes Pond has become a story that has passed from one generation to the next. In 1958, the Klu Klux Klan planned to hold a rally in a local town. Many Lumbees showed up at the planned rally, and quickly dispersed a crowd of KKK members, thus preventing the group from gaining a foothold in our community. Ask most Lumbees about this significant event, and many can share a personal story involving a family member who was there for this famed event. This event became an integral part of who we are as an Indigenous people--modern-day warriors, unafraid to face a perceived enemy. As Ladson-Billings (2016) noted, "Historically, storytelling has been a kind of medicine to heal the wounds of pains caused by racial oppression" (Ladson-Billings \& Tate, p. 57). During the turbulent times of Civil Rights and the Jim Crow laws, it is this story that reminded Lumbees of the strength they held in numbers.

\section{Storytelling Inside of the Classroom-Inside Stories}

Stories told inside of the classroom are usually repeated outside of the classroom and vice versa. Those stories range from creating feather headdresses in November to teachers telling students that they need to speak proper English. To provide a real-world example, the following vignette is offered. 
There is the little girl that is happy to have the "real" Indian headdress, prancing into her mother's arms, yelling look what I made today mom. And, then there is the little Indian girl who knows her history and the pride of her people because of family stories. To avoid disappointing her teacher, this little Indian girl compliantly makes the headdress. Yet, before she boards the bus to head home, she makes sure to stash her newly made headdress in the nearest trash can; she knows if she brings this piece home her mother will become livid because her teacher has belittled their culture. The little girl learned last year the depth of her mother's anger when she brought home a teepee she made in class. Incensed, her mother drove to her school and proceeded to educate everyone on the insensitivity of this activity. The little girl can't help but sadly think why her school is still allowing these activities to take place.

Basically, we have endured non-Indians defining our role in American history for far too long. The narrated stories inside of the classroom should mirror the stories outside of the classroom from all perspectives, including academia and emotional and social behaviors. Allowing others to cherrypick the Indigenous narrative for our native students is paramount to cultural suicide.

\section{Storytelling Outside of the Classroom-Outside Stories}

To disrupt traditional education, educators must think outside of the box; we must become innovators and agitators. The COVID19 Pandemic certainly is reforming education in ways that we never imagined. The stories of our Lumbee people keep us centered, valued, and encouraged. According to Lowry (2018) "Most Indian people do not agree that their elimination-or that of their histories and stories-is necessary for liberty and equality to thrive, but they are unavoidably entangled in these historical assumptions" (p. 9). Our greatest hope is that the issues that continue to expose inequities, social injustices, microaggressions, and oppressions can be steered toward creating a pathway of pedagogy that serves as "justice for all". To provide a real-world connection, the following vignette is offered:

Excitedly, a young Lumbee girl rips into the Amazon package left on her front steps. She doesn't even bother going into the house; she sits outside in the bright sunshine and pulls out her prized possession from the depths of the small cardboard box. She has been waiting on this delivery for several days. Smiling, she runs into her home and shows her mom the book written by a Lumbee for the Lumbee-Whoz Ya People. Her excitement is almost palpable, and she badgers her mom all through supper and clean-up to "hurry up." She can't wait to dive between the covers of the book that holds her uniqueness in its pages. Finally, her mother begins to read the book in her "Lumbee Voice," giving every 
word its Lumbee lilt. Her mom's Lumbee dialect lovingly captures words such as honey, she sewed the finest quilts, come sit with me a spell, and, of course, whoz ya people. As the mom-daughter duo read the book, they discuss the authentic visual representations of Indigenous people, and the little girl feels a sense of relief to finally read about herself in something as majestic as a book. Finding her authentic self in the pages of a book solidifies her Lumbee uniqueness. As her mother wraps up the story, she turns to her daughter, pulls her in her arms, and encourages her to indulge in her own storytelling by posing the question, "Now, whoz ya people?"

Stories as this and the many stories outside of the classroom have a way of validating our cultural teachings. Lowery (2018) asserted, "When we allow stories to breathe, when we reflect on them and analyze them purposefully, we create a society that remembers, not as through a mirror darkly, but face to face, fully, even as we are fully known" (p. 12). Our stories become a part of our identity.

\section{Summary}

In the Lumbee tribe's quest for full recognition, many detractors note that the Lumbee have lost all ties to a tribal identity. The tribe has been accused of "not being Indian enough" to meet federal guidelines. Full federal recognition would provide much needed resources for education and healthcare access. While many Lumbees have resigned themselves to a second-class citizenship status in terms of being identified as Indigenous by the U.S. government, it doesn't hinder those unique factors that tie us together as an Indigenous people. One unique asset that we have is our oral history. What would happen if that, too, was snatched from us? Thus, we offer alternatives to mainstream education that historically defines us. Through the use of digital storytelling, Lumbee youth are offered a way to actively refute and disrupt past historical narratives, and they are allowed to explore and highlight the most important aspects of what makes them uniquely Native, uniquely Lumbee.

\section{Methods}

Grande (2015) asserts, "The formal education of American Indians is at a crisis level; it is not acceptable to have schools fail a large number of students and get away with it" (p. 40). This assertion can be supported by a report disseminated annually by The North Carolina State Advisory Council on Indian Education. The 2020 report, In pursuit of educational excellence for all American Indian students in North Carolina, clearly indicates Indian students lagging their White peers on state mandated test. Opening a space for learning, connection, and revitalization is vital for our Indian youth; thus, we introduce Unlocking Silent Histories (USH). The mission of USH is to 
provide youth digital opportunities to critically analyze their representations in media and express their Native lens.

Local knowledge and voice are foundational to authentic learning. Community-connected themes encourage critical and creative expression. Youth can direct their learning and author their own stories. (DeGennaro, 2016)

USH offers Lumbee youth opportunities to craft and share their own digital narratives; subsequently, the goal is to counter the false narratives perpetuated in the traditional classroom. Rossiter and Garcian (2010) pointed out that the use of digital stories has been offered as an alternative to traditional methods of capturing students' ideas or beliefs such as surveys. Scroggie (2009) explains,

Traditional stories have been passed from generation to generation through folktales, songs, rituals, chants and even artifacts. These oral narratives are critical historical components that pre-date written words. They explain the culture and how it came to be. (p. 76)

To create their own narrative, participants were exposed to a variety of tools for creating a digital story on a laptop. More specifically, Adobe Premiere, Google Drive, Video Cameras, SD Disks, and Tripods were used to complete the digital stories with far more technology and personal skills than when the participants started. Lambert (2010) asserted that digital storytelling has a history of providing a space for reflection and empowerment. Therefore, we simply opened a space for digital storytelling.

The implementation was federally grant funded by Project 3C, awarded to the Lumbee Tribe of North Carolina by the U.S. Department of Education's Office of Indian Education. Project $3 \mathrm{C}$ is a consortium of the Lumbee Tribe, the University of North Carolina at Pembroke, Robeson Community College, and the Public Schools of Robeson County offering Science, Technology, Engineering, and Mathematics (STEM) opportunities for American Indian students. (Project 3C, n.d.)

Unlocking Silent Histories: Lumbee Filmmaking pilot took place during the summer of 2019 on the campus of the University of North Carolina at Pembroke. Ten vibrant Lumbee participants, ages 11-20, engaged in USH's two-week summer camp workshops. During these two weeks, participants delved into their Indigenousness-those characteristics that make them uniquely Lumbee. The participants brainstormed topics in lively, interactive sessions that brought to the forefront their immediate concerns about being Indigenous. They spent several sessions dialoguing with each other about their unique history, and the stigma that being Lumbee can 
bring. Many expressed their fear of the high crime and poverty rates, while others proudly discussed how they were on a campus that was originally built for Native students. These sessions birthed a plethora of potential documentary ideas, and USH facilitators provided opportunities for these enthusiastic youth to explore the pros and cons of their documentary options.

Using an interpretative analysis approach through digital storytelling we (re)shape, (re)claim, (re)write, and (re)form the framework of Indigenous education. While the alternative classroom was a hub of ideas, discussions, and light-hearted debates, the multiple journeys into the field provided participants with an in-depth perspective of the geography of our surrounding communities. These field journeys provided even richer opportunities for participants to expound upon their Indigenousness. Participants closed by presenting six film debuts in which our data collection and analysis draws upon the blend of two frameworks, constructivist research (Guba \& Lincoln, 1989) and personal digital stories (Lambert, 2003; Robin, 2008). Our interpretive analysis (Corbin \& Strauss, 2015) assists us from an ethnohistorical (Brayboy \& Deyhle) viewpoint to contribute to Indigenous narratives, voice, and educational practices, decolonizing (Smith, 2012) conventional approaches to mainstream education.

\section{Findings}

Our analysis of Project $3 \mathrm{C}$ and Lumbee youth utilizing the pedagogical approach of Unlocking Silent Histories (2016) informs and reveals the power of rethinking traditional education for our Native youth. Using the youths' digital documentaries as a means to explore what their Indigenousness means to them, we were able to identify emerging themes from the holistic perspective of the Lumber River, Community, and Resilience.

\section{Lumber River}

"The blood of Lumbee ancestors is in the sandy loam and black water of our homeland along the swamps and streams flowing from the Lumber River" (Lowery, 2018, p. 243). It comes as no surprise that the Lumber River emerges as a recurring theme in the film analysis conducted. Emanuel (2019) emphasizes the relationship the Lumbee have with the Lumber River stating,

Robeson County lies almost entirely within the Lumbee River basin and is the seat of the Lumbee community. In Robeson, every road that goes anywhere eventually crosses a river or swamp. (p. 32)

The river is a physical, as well as spiritual, part of the Lumbee people. The Lumber River has served many purposes for the Lumbee, and it is an integral part of who the Lumbee are. The river has offered itself as a sanctuary, and it has also provided a bountiful sustenance for fishers. The 
river is also a means of recreation for many Lumbee families. In summation, the Lumber River serves as a symbolic oasis for the Lumbee people. Emanuel (2019) notes,

Lumbee people respect and honor the river, and they spend time in and around its waters for work, recreation, and worship. In doing so, the people and the river have each infused the other with identity to the extent that both share the same name. (p. 29)

Thus, it is important to note that the Lumbee people refer to the river as the Lumbee and the Lumber. In the film, Symbols of the Lumbee Culture, Dr. Mary Jacobs suggests that, "because the river was here, that's the reason we were here" (2:57). It is this symbiotic connection that drives the relationship of the Lumbee people and the Lumber River. While the river serves as an overarching theme of the film data analysis, two sub-themes are discovered as supporting evidence: (a) Historical Trauma/Effects of the River and (b) Leveraging the River's resources.

\section{Historical Trauma/Effects of the River}

In 2016, Hurricane Matthew pummeled Robeson County mercilessly. After relentless rains, came the flooding. The storm left many with flooded homes, crops, and businesses. Robeson County was devastated. After Matthew, Robeson County residents settled into an uneasy alliance with the Lumber River. While the river had destroyed so much, it still provided so much to the local area, especially the Lumbee. Then, in 2018, came word that Hurricane Florence was headed our way. This time around residents felt more prepared to handle the punishing floods. After all, they had managed to survive Matthew, albeit a bit bedraggled and weary. Again, Mother Nature surprised its residents with just how powerful the rushing waters of the Lumber River could be. Hurricane Florence lashed through our county, heedless in her force. This storm wreaked havoc in an area still reeling from a storm two years prior. As one interviewee notes in the film The Lumber River (2019), "She's a place of beauty, she has so much potential, but she can also be a destructive force" (:10).

The film, The Lumber River (2019), offers the most insight into the trauma that these two storms wrought on its Native inhabitants.

Two interviewees stand on the banks of the Lumber River. In the background, the rivers dark waters are readily visible. Both interviewees intermingle their pleasant childhood memories with memories of the punishing floods. One interviewee notes of the historic flooding: "She rolled off her banks and she took people's homes, she took people's lives, she took people's livelihoods". (1:50) 
In this excerpt, video data support the historical trauma of the river despite the significant Lumbee connection to the landmark.

\section{Leveraging the River's Resources}

Ask any local Lumbee where they can find a "honey hole" and many will offer you several suggestions from which to choose. "Honey holes" are prime swimming spots where the water appears to have a honey-like sheen, and there is an easy way to access the river. These "honey holes" are used for sheer recreation. Swimming and fishing are the main sources of entertainment. Folks also use these spots to hang out, chew on the day, mingle with friends, and enjoy a cold beverage. One interviewee, in the film Lumber River, notes, "I think it's a place for community and fun, and I mean people come back here and fish, and just enjoy their families" (2:31). Another interviewee in this film notes, "I see this river that flows behind me, and it brings up so many childhood happy memories of Lumbees gathering at the river to wash, to laugh, to share stories about their day" (2:14). Even though the river has wrought damage over the last few years, many still seek refuge by her banks. When she is contained and quiet, she serves as a reminder of the glory of nature.

Summary

The Lumber River serves as a major touch point in the film analyses. Interviewees note how the river has served the Lumbee people throughout the centuries. Historians note that the Lumbee Tribe owes its existence to the river from serving as a food source and entertainment to becoming a hindrance to the Native way of life. The Lumber River serves as a deeply rooted connection to the Lumbee people and understanding Lumbee's historical relationship with the river is necessary.

\section{Community}

Community is of great importance to the Lumbee. Internal communities are established within the Lumbee people based on location, family, and school and church enrollment to name a few. Lowery (2009) supports this claim in dissertation studies on identity, asserting,

I knew that the Lumbee community was proudly and stubbornly decentralized - within the larger community are many smaller communities formed around families, special places, and economic and religious interests. (p. 500)

Community is who the Lumbee are and how we self-identify within the larger population. For example, one may say I am from the Prospect community or my father is from Chapel. Details as these connect the Lumbee to the smaller communities. To support the emerging theme of 
community, we provide evidence by discussing two aspects: (a) farming and (b) the Lumbee accent.

\section{Farming}

At one point, farming was the chief occupation of Lumbees. Many farms have been in Lumbee families for multiple generations. Lumbees have a strong tie to the land and utilizing the land for farming was extremely advantageous to the Lumbee. In the film titled, The Lumbee People: The Color of the Sun (2019), one interviewee describes how her Indianness is anchored in farming. She asserts, "To be a Lumbee Indian, I was raised in a farming area, and, umm, we know a little about everything farming, and how to take care of things" (4:33).

Lumbee people have farmed these sandy uplands for generations, clearing fields among loblolly and longleaf pines to cultivate a variety of crops, both for income and subsistence. Lumbee farmers historically grew corn, cotton, tobacco, and other cash crops, as did many of the non-Indigenous farmers of the region. Home gardens and medicine cabinets of Lumbee families were supplemented by a variety of wild foods from adjacent rivers, swamps, and wetlands. Blueberries and other wild berries, native to the moist, acidic Carolina bay soils were harvested in warmer months (Emanuel, 2019).

In the film Native Poverty (2019), one participant notes that, while her family was poor, food was not an issue because of farming. "When I was growing up in the family, there was 12 in the family, but I grew up with eight of us still at home. Growing up we had plenty of food, cause I grew up on a farm. We had our meats and vegetables" (:59). In several of the films, many of the interviewees remember the hard work of farming, and how it served as a central part of Lumbee life growing up. While many of the participants lamented the hard work, they also acknowledged that there was a certain contentment gained from working the land and providing food for the family.

Lowery (2019) discusses a "critical part of Lumbee identity and independence as being landowners" as our people are proud to own and farm their own crops on their own land (p. 104). When asked about iconic symbols of the Lumbee people, one participant who works at the Native American museum on UNC-Pembroke campus notes that items related to farming serve as an iconic and symbolic reminder of the Lumbees relationship with farming. "We have any representation that is connected to farming, especially tobacco farming, so things like tobacco tie sticks or items related to cotton (Symbols of the Lumbee People, 2019, 1:49). These artifacts connect the Lumbee to community. 


\section{Accent as a Community Anchor}

How you doin, pa? (:13),

Fetch me the bucket o' water (:15),

Gah da honey, what was dat you said? (:23),

Honey chile, where you been (:30),

A little bit of dis and dat (:38), (Lumbee Accent, 2019)

Ask most people to identify the region in which these statements were uttered, and many would be hard-pressed to pinpoint where this regional dialect was spoken. Yet, for those who live in the Lumbee community, this type of spoken language is an everyday occurrence. The unique Lumbee accent anchors us to one another, and, in turn, it anchors us to our community. In the film titled, Lumbee Accent (2019), one participant describes being at a drink machine in California. While there, an attendant refilling the machines hears her speak. He proceeds to tell her that he knows she is from North Carolina, and more specifically he can tell her not only which part of North Carolina that she is from, but he is also able to tell her that she is part of the Lumbee tribe. Thousands of miles from home, a stranger can identify, not only the regional residence of this person, but he can also describe the tribal affiliation. In the film, The Lumbee People-The Color of the Sun one interviewee notes, "It's kinda hard to describe, but you can be anywhere in the United States, anywhere in the world and identify a Lumbee quickly, not necessarily based on their skin color or hair texture, but just by their actions, and of course when you hear them talk" (1:20).

The Lumbee accent has a way of connecting you to your people. According to Locklear, L.A. (2017), "not only does the pronunciation and sentence formation of sentences create a way of speaking that may seem strange to outsiders, the Lumbee also evoke a vocabulary of their own" (p. 99). Video data supports this assertion as an interviewee in the film Lumbee Accent (2019) states,

It is its own little language that we and others of Native culture understand, and whereas other people would be kinda confused on what you're saying but you can talk to another native person and they know exactly what you're saying, what you're referring to (2:11).

While the way we speak may not be tangible enough for the United States government to give us Federal status, it is enough for the Lumbee people to share a unique kinship with one another based on the way we speak. The Lumbee accent serves as a strong identifier, inexplicably tying Lumbees to each another. Our accent is a recognizable characteristic, and it serves as a way for individuals to connect with each another on a deep and personal level. 


\section{Summary}

The film analyses merely supports what the Lumbee have long contended as their uniqueness. The ties to farming, and their distinct accent are ways the Lumbee feel that their Indigenousness is displayed. For the Lumbee community, farming staved off hunger; farming was an honorable endeavor because it provided food on the table. Though poverty is rampant in the community, fresh food, especially in the summertime, is readily available for those willing to work for it. The community takes care of its own. And, while to outsiders, our accent may be off-putting for those who do not live in the community, for those of us who live in the community, it is a sweet, melodic reminder of our connection to one another. Farming and accent are reminders that we have strong connections to the land and to each other.

\section{Identity}

While Lumbees are easily recognizable to one another, there are struggles within the community in terms of identity. As Lowery (2019) asserts, 'Our people' is more than an idea; it's an observable network of kin and family. Family of full of complexities and conflicts" (p. 41). Those same complexities and conflicts unfold identity issues as well. Two identity struggles emerge from the video analyses conducted by the researchers. One of those struggles is skin color. Some participants discuss how being a certain skin tone impacted their lives. Another struggle that emerges is how members of the Lumbee community deal with the ramifications of the Lumbee accent. While accents are considered an identifier among Lumbee people, in other settings, the accent is considered a form of unacceptable English.

\section{Colorism}

Colorism most notably exists in the African American culture. Colorism is the idea that the lighter your skin tone, the less prejudice one will experience in mainstream society. While most people associate colorism with African Americans, it is also prevalent amongst the Lumbee. Historically, light skinned Lumbees found it easier to navigate the Jim Crow south. For example, if a Lumbee was light-skinned enough, he or she could sit in the "White" only section of the movie theater, or they could partake of "White" only restaurants. There were many advantages to being light-skinned during the Jim Crow era. If you were a "White" Lumbee, you were gifted with an amazing advantage-a way to slip in and out of white society almost unnoticed.

As society shifted and changed, there was a noticeable shift in Lumbee's attitudes towards skin color. Suddenly, being "pecan tan" was preferable to being "white." In the film, The Lumbee People-The Color of the Sun, one interviewee discusses his struggles growing up as a lighter complected Native. He says: 
I experienced colorism growing up. Being a lighter complected Native American I was often called light skinned Indian boy and white boy were terms used. A lot of my older relatives, individuals at school, kids at school that kinda became an on-going thing as if you were lighter complected and Native you were just termed as the light-skinned white boy. Of course, that equates to being bullied and equates to self-esteem problems and such. (1:59)

It is evident that, while this bullying occurred several decades ago, this interviewee still harbors the pain associated with being an outcast based on his skin tone.

In another segment of the video titled, The Lumbee People-The Color of the Sun one young participant describes the other side of colorism-the one in which you can also be deemed too dark to be Lumbee. She notes, "A Lumbee can look like anything. They can have light-skin, or dark skin like me-it don't really matter, but a lot of people judges us like that" (3:21). As the young interviewee shifts her eyes downward, the audience can almost palpably feel her hurt as well.

The excerpts from these videos highlight the divisiveness that can occur within the Lumbee community concerning skin color. The melanin factor is a very real issue, and it insinuates itself in very painful ways in the Lumbee community.

\section{Code-switching}

Code switching is a unique trait of the Lumbee community. Lumbee people must translate their language for outsiders. And, often, we code switch to connect with outsiders. To define the term, code switching is the taking of the spoken home language and transferring it into a more formal English dialect. This occurs most often in professional settings as the Lumbee accent is not always celebrated. Rather, the accent, at times, becomes a hurdle for Lumbee folks. One interviewee states, "I remember when I spoke and how everyone kind of cringed like I had committed a crime or something" (Lumbee Accent, 2019, 4:00).

Negative reactions to the Lumbee accent creates an inner struggle for the Lumbee. While many don't want to give up this natural way of speaking, many know that they have to in order to flourish in mainstream society. Thus, many Lumbee people steer away from their accent, mimicking "good" English. An interviewee referenced this mimicking in Lumbee Accent, 2019, asserting

I purposely listened to the language patterns of educators who worked in the school system, and I knew that I would have to make some kind of changes in order to do a decent job interviewing (3:43). To add the interviewee stated, To fit in, I would change 
pronunciation, dialect, accent in order to fit in and belong and in some cases to even get a job (4:23).

This type of codeswitching is necessary as some outsiders' frown upon the Lumbee accent and many erroneously make the generalization that the Lumbee are less intelligent than their counterparts. One interviewee specifically states, "I think individuals are sized up by the way they speak" (Lumbee Accent, 2019, 4:47) as another adds, "I practice with my kids code-switching because I don't, I don't want them to face the same discrimination that I faced" (4:50).

For the Lumbee, being able to code-switch can mean the difference between having a livelihood or not. It can mean the difference between being accepted in a social setting or not. There are very real and negative ramifications for individuals who choose not to code-switch in professional settings. Even though our accent highlights our tribe's uniqueness, we are still required to camouflage it so that we can "fit in."

\section{Summary}

Being marginalized is not a new phenomenon for the Lumbee; we have been marginalized for centuries, and we have fought for a place at the Indigenous table for decades. Being chastised by outsiders because of the way we speak is another way we are marginalized. Being marginalized within the tribe can be especially painful for individuals because finding acceptance anywhere becomes extremely troublesome. When your own tribe mocks you because of your skin color, how do you fit in elsewhere? For the Lumbee, marginalization can take place outside the boundary, as well as inside the boundary.

\section{Resilience}

In Hunt's (2020) review of The Lumbee Indians: The American Struggle she asserts, "Despite the losses of wars and of leaders, the Lumbee remain resilient, always adapting and yet always resisting" (p. 120). There is not a Lumbee lesson, module, or professional development on encountering the world the Lumbee way. For Lumbee youth raised in the territory, the Lumbee way is as natural as breathing. Things become muddied when outsiders attempt to disrupt the Lumbee way of life. Things happen in education that are gut-wrenching such as racism, discrimination, and microaggressions. Video data offer the voice of an interviewee,

I think it was the first night of class, and I can't remember the professor's name but the professor asked was there any students from the Prospect community, and if so, he wanted you to raise your hand and ummm, he wanted you to stand up and talk for the other students to hear you. (Lumbee Accent, 2019, 3:09) 
Occurrences like these should not be a part of education, or the world for that matter. Who is standing in the gap for our Lumbee youth? What individual is admonishing professionals in positions of power who tell the Lumbee youth that the Lumbee way is unacceptable. Lumbees find themselves struggling to find balance between their culture and mainstream society. One interviewee observes the paradoxical nature of the Lumbee accent, "I think we should be true to ourselves and true to our culture and I know when I'm around my family and Lumbee friends I kind of let my hair down and I don't code-switch as much" (Lumbee Accent, 2019, 4:59), and I try to be very conscious of my accent (4:07). These types of calibrations create resilience within and for our Lumbee people.

Whether in elementary, middle, high school, or the college setting, things happen in education that create inert feelings of consciousness for the Lumbee. If we do not respond to our conscience, creating resistance, then we allow mainstream society to dictate the appropriate curriculum for our youth. Further, we allow this to happen when we ask for a seat at the "decision" table to be a voice of color rather than creating a table of our own. The Lumbee people have been constructing their very own table for quite some time. Hence, the establishment of the University of North Carolina at Pembroke. And, this is the resilience that matters.

\section{Discussion}

In this article, we offer authentic teaching and learning opportunities to Indigenous youth by simply opening a space to craft their own narratives for their own people through digital storytelling. The stories not only interrupt the Columbus narrative that continues to seep into Indigenous communities, but equally important, the digital stories also create a space for documenting our history. The film analyses reveal common and recurring themes in our community, and these documentaries reflect how knitted we are in our indigenous community. King (2003) suggests that "once a story is told, it is loose in the world. So you have to be careful with the stories you tell. And you have to watch out for the stories that you are told" (p. 10). Through our examples and film analyses, we demonstrate the power of originating perspectives individually and collectively. As Lowery (2018) asserted, “...stories now serve to recall our power to find solutions, to point our way forward as a Lumbee and American people" (p. 243). Advancing critical consciousness within Indigenous communities is one hope of this digital storytelling project.

This critical consciousness empowers Indigenous voice; (re)shaping, (re)claiming, (re)writing and (re)forming traditional education practices. The Unlocking Silent Histories pedagogical design allows Indigenous youth opportunities to resist linear ways of teaching and 
learning. Pedagogy is shifted to a non-structured approach fostering an open-ended learning experience that is connected to the land, people, and inner being. The composed, yet flexible, program lends way to progression and the shedding of light on decolonized approaches to education. As youth experience this shift, ironically, there are power struggles. The internal conflict of thinking and doing in a less controlled, less colonized, less assimilated, less linear way brings critical consciousness to the forefront.

The USH pedagogy aims to connect Indigenous youth with their individual perspective. Within the experience, Indigenous youth unconsciously un-learn some teaching styles that they have been accustomed to in the traditional education environment. As the youth disconnect from traditional ways of teaching and begin to connect with their Indigenous worldview, they develop a critical lens for teaching and learning. This critical lens is paramount for developing and redesigning curriculum that can potentially close achievement gaps. For the Lumbee community, the advancing of critical consciousness is of utmost importance. By providing an analyses of the digital documentaries created by our Lumbee youth, we lend credence to the notion that our community should disrupt and challenge the traditional teaching methods that our Lumbee children encounter in the classroom. These documentaries serve as a reminder that our Lumbee youth have a story to tell about who we are as a people. If not for this opportunity, would these Lumbee youth have a chance to tell their story in a traditional teaching environment?

Reflecting on the Lumbee way, Lowery (2018) writes “Lumbees everywhere are succeeding as individuals and becoming problem solvers, and they are doing so in many areas to include education" (p. 242). COVID-19 pressed educators to transform "traditional" education. As education is entering the transformative stage, Indigenous scholars must take a stand to rethink the way we educate Indigenous people. And, you know what? Rethinking is not enough. It is imperative that Indigenous scholars begin to advocate and execute a culturally responsive design that we know to be necessary for our youth to excel in all ways.

\section{Authors' Note}

Tiffany M. Locklear, School of Education, University of North Carolina at Pembroke. Frances D. Hunt, School of Education, University of North Carolina at Pembroke.

This research was supported by a grant from Project 3C, a grant awarded to the Lumbee Tribe of North Carolina by the U.S. Department of Education's Office of Indian Education. Project $3 \mathrm{C}$ is a consortium of the Lumbee Tribe, the University of North Carolina at Pembroke, Robeson Community College, and the Public Schools of Robeson County offering Science, Technology, 
Engineering, and Mathematics (STEM) opportunities for American Indian students. (Project 3C, n.d.)

Correspondence concerning this article should be addressed to Tiffany M. Locklear, School of Education, University of North Carolina at Pembroke, Pembroke, NC 28372. Contact: tiffany.locklear@uncp.edu.

\section{References}

Brayboy, B., \& Deyhle, D. (2000). Insider-outsider: Researchers in American Indian communities. Theory Into Practice,39(3), 163-169. Retrieved from http://www.jstor.org.liblink.uncw.edu/stable/1477548

Datta, R. (2018). Traditional storytelling: An effective Indigenous research methodology and its implications for environmental research. AlterNative: An International Journal of Indigenous Peoples, 14(1), 35-44. https://doi.org/10.1177/1177180117741351

DeGennaro, D. (2016). Designing critical and creative learning with Indigenous youth: A personal journey. Sense. https://doi.org.1007/978-94-6300-307-0

Emanuel, R. E. (2019). Water in the Lumbee world: A river and its people in a time of change. Environmental History, 24(1), 25-51. https://doi.org/10.1093/envhis/emy129

Grande, S. (2015). Red pedagogy: Native American social and political thought. Rowman \& Littlefield.

Guba, E. G., \& Lincoln, Y. S. (1989). Fourth generation evaluation. SAGE.

Hatch, J. Amos. (2002). Doing qualitative research in education settings. New York Press.

Hunt, B. (2020). The Lumbee Indians: An American struggle by Malinda Maynor Lowery. The American Indian Quarterly, 44(1), 118-120.

King, T. (2003). The truth about stories: A native narrative. House of Anansi Press.

Ladson-Billings, G., \& Tate, W. F. (2016). Toward a critical race theory of education. In Critical race theory in education (pp. 10-31). Routledge.

Lambert, J. (2003). Digital storytelling cookbook and traveling companion. Digital Diner. Retrieved May 2, 2007, from http://www.story center.org/cookbook.pdf 
Lambert, J. (2010). The digital storytelling cookbook. Digital Diner Press.

Locklear, L. A. (2017). Healing: The Stories of Academic Successes and Barriers Faced by Lumbee Tribal Young Adults. The University of North Carolina at Greensboro.

Locklear, T. M. (2017). Decolonizing Methods of Culture and Learning Within the Lumbee Community (Doctoral dissertation, University of North Carolina Wilmington).

Lowery, M. M. (2009). Telling our own stories: Lumbee history and the federal acknowledgment process. American Indian Quarterly, 33(4), 499-522.

Lowery, M. M. (2018). The Lumbee Indians: An American struggle. UNC Press Books.

Northwest Comprehensive Center (2018). Every student succeeds act tribal consultation pre planning tool for tribes. Retrieved from https://nwcc.educationnorthwest.org/sites/default/files/essa-tribal-consultationpreplanning-toolkit.pdf

North Carolina Department of Public Instruction. (2020). 2020 Vision for Culturally Responsive Classrooms through Tribal Consultation (Our Land, Our Stories, Our Future) (pp. 176). Raleigh, NC.

Project 3C. (n.d.). Retrieved from https://www.uncp.edu/resources/southeast-american-indianstudies/initiatives/project-3c

Robin, B. R. (2008). Digital storytelling: A powerful technology tool for the 21 st century classroom. Theory into practice, 47(3), 220-228.

Rossiter, M., \& Garcia, P. A. (2010), Digital storytelling: A new player on the narrative field. New Directions for Adult and Continuing Education, 126, 37-48.

Scroggie, A. M. (2009). Preserving tradition and enhancing learning through youth storytelling. Journal of Bhutan Studies, 20, 76-92.

Smith, L. T. (1999). Decolonizing methodologies: Research and indigenous peoples. University of Otago Press/Zed Books

Unlocking Silent Histories. (2016). Unlocking silent histories: Critical and creative expression for Indigenous youth. Retrieved from http://unlockingsilenthistories.org 
Unlocking Silent Histories. (2019, June). Agriculture [Video File]. Retrieved from https://vimeo.com/350319039

Unlocking Silent Histories. (2019, June). Lumber River [Video File]. Retrieved from https://vimeo.com/350319800

Unlocking Silent Histories. (2019, June). Lumber River [Video File]. Retrieved from https://vimeo.com/349656582

Unlocking Silent Histories. (2019, June). Native Poverty [Video File]. Retrieved from https://vimeo.com/350348583

Unlocking Silent Histories. (2019, June). The Lumbee Indians; The Color of the Sun [Video File]. Retrieved from https://vimeo.com/350327042

Unlocking Silent Histories. (2019, June). Symbols of the Lumbee Culture [Video File]. Retrieved from https://vimeo.com/350238534

Wolcott, H. F. (2008). Ethnography: A way of seeing. (2nd ed.). Altamira Press 